She was para $3+0$. The second was a twin pregnancy. All four children were alive and well. Her last menstrual period was on 6 July 1968 . The uterine size was compatible with the period of gestation. On 22 October 1968 hysterotomy and Pomeroy sterilization was performed by an experienced member of our team. A single fctus was removed from the uterine cavity, and the postoperative period was satisfactory apart from mild urinary tract infection.

At the follow-up clinic on 27 December 1968 the patient presented with a uterus the size of a 24-week gestation. She was obviously pregnant and she was booked for a hospital delivery. On 1 February 1969 she was admitted in premature labour and had a spontaneous delivery of a live infant weighing $3 \mathrm{lb}$. $(1.4 \mathrm{~kg}$.) The puerperium was normal. The infant continued to thrive.

Although it cannot be proved, there is strong circumstantial evidence that this was a twin pregnancy and that only one gestation sac was removed at the time of hysterotomy. The other fetus must have continued to thrive. As far as I am aware a similar case has never been previously reported. The medicolegal implications of such a case are obvious, and I would suggest that everyone undertaking such a procedure should search for a second gestation sac and make appropriate notes at the time of operation.-I am, etc.,

Satya V. Sood.

Department of Obstetrics and Gynaecology, West Middlesex Hospital,
Isleworth, Middx.

\section{L-dopa for Postencephalitic Parkinsonism}

SIR,-In recent months there have been several trials on the efficacy of L-dopa in the treatment of Parkinson's disease. Few of these have referred to postencephalitic Parkinsonism and it has been noted that patients in this group do not tolerate Ldopa as well as patients in whom the disorder is of a different origin. ${ }^{1}$

L-dopa is now freely available to hospital and general practice. Fortunately, most manufacturers temper this free availability with a note of caution, such as: "Long term safety and efficacy have yet to be established."

We wish to present our own findings in a nine-week trial of this preparation in twelve patients with postencephalitic Parkinsonism who have manifested signs of their condition for between 10 and 49 years. There were six women and six men, and their ages ranged from 50 to 70 years. Treatment with traditional therapy (benzhexol and orphedadrine) was continued.

The Table shows the dosages employed (these were given in divided doses three times daily with meals), the duration of treatment, the effects on tremor, rigidity, and writing ability, and also the side effects encolntered during the trial The side effects which may be seen with this drug are reviewed elsewhere, ${ }^{2}$ but those most frequently seen in the present study were nausea, vomiting, psychological disturbances, and involuntary movements. Among the last were facial grimacing, tongue protrusion, and foot stamping; and eight out of twelve patients exhibited some kind of emotional upset, including euphoria, depression, aggressive and antisocial behaviour, hallucinations, and delusions.

Of the twelve patients who commenced treatment, therapy was withdrawn in eight patients because of side effects, seven showed no response at all, three showed substantial improvement,

\begin{tabular}{|c|c|c|c|c|c|c|c|}
\hline \multirow{2}{*}{ Patient No. } & \multirow{2}{*}{ Age } & \multirow{2}{*}{$\begin{array}{c}\text { Stabilized } \\
\text { Daily Dosage } \\
\text { of } \mathrm{L} \text {-dopa (mg.) } \\
\end{array}$} & \multirow{2}{*}{$\begin{array}{c}\text { Duration of } \\
\text { Treatment } \\
\text { (Days) }\end{array}$} & \multicolumn{3}{|c|}{ Effect on } & \multirow{2}{*}{ Side Effects } \\
\hline & & & & $\mathbf{T}$ & $\mathbf{R}$ & W & \\
\hline $1 \quad$. & 54 & 1,500 & $63^{*}$ & O & 0 & 0 & Depression; nausea; grimacing \\
\hline $2 \quad$. & 60 & 750 & $63^{*}$ & + & $\mathrm{O}$ & + & Depression; uncooperative; nausea \\
\hline $3 \ldots$ & 53 & 1,500 & 28 & 0 & + & O & $\begin{array}{l}\text { Exhibitionism; more oculogyric crises; } \\
\text { involuntary foot stamping; } \\
\text { hemiballismus; nausea }\end{array}$ \\
\hline $4 \quad \ldots$ & 56 & 750 & 8 & 0 & 0 & 0 & $\begin{array}{l}\text { Mouth twitching; screaming and } \\
\text { weeping attacks; respiratory panting }\end{array}$ \\
\hline $5 \quad \ldots$ & 64 & 1,500 & 36 & O & O & $\mathrm{O}$ & Nausea and vomiting \\
\hline $6 \quad$. & 57 & 1,500 & $63^{*}$ & $\mathrm{O}$ & O & $\mathrm{O}$ & $\begin{array}{l}\text { Involuntary movements of tongue; } \\
\text { withdrawn }\end{array}$ \\
\hline 7 & 70 & 1,500 & 28 & ++ & ++ & + & $\begin{array}{l}\text { Aggressive and uncontrollable; } \\
\text { exhibitionism }\end{array}$ \\
\hline $8 \quad$. & 69 & 4,500 & 51 & 0 & ++ & $+t$ & $\begin{array}{l}\text { None-patient died of acute } \\
\text { bronchopneumonia }\end{array}$ \\
\hline $9 \quad \ldots$ & 58 & 1,500 & 32 & + & ++ & $+t$ & $\begin{array}{l}\text { Nausea and vomiting; euphoria; } \\
\text { thrombocytopenia (Platelets } \\
<10,00 / \text { cu. mm.) }\end{array}$ \\
\hline $10 \quad \ldots$ & 50 & 1,500 & 32 & $\mathrm{O}$ & 0 & $\mathrm{O}$ & $\begin{array}{l}\text { Involuntary protrusion of tongue; } \\
\text { respiratory panting; intermittent } \\
\text { penile erection }\end{array}$ \\
\hline $11 \quad \ldots$ & 58 & 1,500 & 33 & 0 & 0 & 0 & Involuntary protrusion of tongue \\
\hline $12 \quad \ldots$ & 61 & 2,000 & $63^{*}$ & + & + & + & Hallucinations and delusions \\
\hline
\end{tabular}

and two showed moderate improvement. It is noteworthy that in all three patients who benefited conspicuously, the drug had to be discontinued because of side effects. Four patients remain on treatment.

Some of the side effects of this drug will obviously necessitate withdrawal, but the less troublesome ones may be controlled by appropriate adjustment of dosage and the addition of dopa-decarboxylase inhibitors; ${ }^{3}$ these were not used in the present trial.

It is confirmed that not all types of Parkinson's disease show equal benefit on treatment with L-dopa. Full assessment of the disability and the planning of treatment should be undertaken in hospital and dosage be cautiously increased to the limits of tolerance. In summary, the use of $\mathrm{L}$-dopa in the treatment of our patients with postencephalitic Parkinsonism has been

attended by the frequent occurrence of unpleasant side effects. The poor tolerance shown by these patients calls for further study.

We wish to thank Professor Stanley Alstead for help and advice in carrying out this investigation. -We are, etc.,

N. KRASNER JANET M. Cornelius.

University Departments of Materia Medica and Geriatrics, Stobhill and Ruchill Hospitals, Glasgow N. REFERENCES

Calne, D. B., Stern, G. M., Laurence, D. R., Sharkey, J., and Armitage, P., Lancet, 1969, 1, Krasner, N., in British Encyclopaedia of Medical Practice, Medical Progress 1970/71-Clinical Pharmacology and Therapeutics (Treatmer
Parkinson's Disease). In press.

3 Tissot, R., Presse Médicale, 1969, 77, 617

\title{
Depression and Oral Contraception
}

SIR,-Dr. Brenda N. Herzberg and her collaborators are to be congratulated on their careful and painstaking attempt to elucidate the difficult problem of depression occurring in women taking oral contraceptives (17 October, p. 142). Some possible sources of error are listed, but my main difficulty in accepting their conclusions lies in the fact that their controls are unmatched.

Broadly speaking, women requesting contraception fall into two groups: those who want virtually $100 \%$ efficiency and those who are satisfied with something less. Excluding certain periods of time associated with massive adverse publicity (for example, late 1969 to mid 1970), into the first group will go the majority of women who have enough or too many children, are unmarried, have had abortions, have suffered from severe physical or psychiatric disease, are either very young or very old (reproductively speaking), and those with unstable family relationships, financial problems, or housing difficulties. To these women a pregnancy would often be a catastrophe, and they therefore choose the reliable pill. Into the second group go the remainder, and, again excluding those frightened off the pill, will be mainly women delaying or spacing their family. To them a pregnancy may be ill-timed, inconvenient, or unwanted-rarely a catastrophe.

In other words, the reason for the development of depression and for the choice of the oral contraceptive method may well be the same. To say that one group can act as controls for the other without taking this factor into account seems to me unrealistic. The difference between these two selfselected groups is quite enough to explain a difference of $6 \%$ in the incidence of severe depression-indeed I would have expected it to be higher than $6 \%$ and it may well be that the freedom from the fear of pregnancy conferred by the pill is the reason for this low figure.

Your leading article (p. 127) is relevant. Not only should the doctor look for symptoms of depression, but should also look for causes other than the pill. Not only should the doctor consider changing or abandoning the oral contraceptive, but should also con- 